\title{
Coping, resilience and posttraumatic growth: adverse childhood experiences and social work students
}

\author{
Glynnis Dykes
}

\begin{abstract}
This qualitative case study explored the perceptions of third-year social work students at a selected university in South Africa regarding the effects of having endured adverse childhood experiences. Findings showed the beginnings of positive life lessons that can emerge from having endured adverse experiences. Findings also confirmed the process of coping with these experiences that included outcomes of resilience and burgeoning posttraumatic growth. Implications are discussed especially regarding the place and development of coping, resilience and posttraumatic growth in social work education and social work practice. Recommendations include the professional use of self and selfawareness through mindfulness teaching practices.
\end{abstract}

\section{INTRODUCTION}

The social work profession has historically focused on the effects of adversity on the lives of people (McMillen, 1999). This focus has often taken the form of emphasising deficit models that are problem-focused and diagnosis-oriented. There has been a fundamental shift with social workers preferring strengths-based approaches and models that accentuate people's abilities and aptitudes when confronted with stressful or traumatic situations (Rodgers, 2014; Saleebey, 2002). Despite the humanistic and value-based emphases of these approaches and models, they mostly underscored individualistic perspectives with a concerted focus on the self (Gray, 2011). Consequently, there has been insufficient attention on the role of macro socio-political structures and environmental conditions in the challenges experienced by the individual (Gray, 2011). This study though does focus on social work students and their social experiences and of necessity will have an individualistic focus because each one's experience is unique.

In a specific South African university, students generally mirrored the social history and experiences of the communities from which they stem that link to the broader South African society (Carelse and Dykes, 2013; Petersen, 2010). The findings of a primary study provided clarity regarding the adverse childhood experiences (ACEs) of social work students: frequent childhood abuses (including physical, sexual and emotional); ineffectual caregiving (parental substance abuse, desertion and absence); poor family wellbeing (in particular family conflict and intimate partner violence); and poor social environments. The significant implications were that they were not aloof from these harrowing incidents 
themselves and that these experiences continued to plague them within the context of social work teaching and learning (Dykes, 2014). These were important findings because of the understanding they provided into the extent and severity of the effects of ACEs on participants. ACEs refer to the negative and often traumatic incidents during childhood that is experienced by a person as negative or traumatising depending on the severity of the particular incident and the impact that is felt by the person (Dube, Felitti, Dong, Giles and Anda, 2003). Thus the event need not be viewed by others as particularly harrowing or disastrous because trauma is a personal judgment (Wade and Schenck, 2012).

Through these initial findings, it was concluded that the effects of ACEs on a person's wellbeing is varied and long lasting, causing emotional, behavioural and physical difficulties. The implication of these findings is that social work students continue to struggle with the effects of childhood adversity, which confirm the contention that the social work class is often a site for their own emotional and behavioural struggles. The motivation for this article is therefore the yin-yang nature of the findings showcasing both adverse effects of ACEs of students as well as positive personal growth.

This article focuses on the perceived posttraumatic growth (PTG) of social work students who participated in a primary study on their adverse childhood experiences (ACEs). The impetus for the primary study was contextualised within social work teaching and learning. The drive behind the focus on the essentials of teaching and learning in social work centred on the emergence of adverse childhood experiences (ACEs) experienced by social work students. The researcher had become increasingly interested in the ways in which these ACEs affected students in social work classrooms and became compelled to explore the processes at play in social work classrooms.

This article, therefore, represents a subset of the primary study focusing on the findings that show that posttraumatic growth could emerge from the ACEs that students had endured. In their research with social work students regarding their coping with academic stress, Wilks and Spivey (2010) concluded that the means of coping comprised social support mechanisms (such as specific family members and friends) whilst the outcome of effective stress management was resilience. This is especially important for the study as it focuses on the effects of ACEs on social work students and therefore socio-emotional qualities and resilience are of special interest. Few studies have focused on social work students' ACEs and the posttraumatic growth that emerged from these. One study focused on undergraduate students but did not relate these to the particular course that they were doing (Taku, Calhoun, Tedeschi, Gil-Rivas, Kilmer and Cann, 2007); whilst others focused on the PTG that emerged from the exposure to social work issues and interventions (Rodgers, 2014; Gibbons, Murphy and Joseph, 2011).

The problem, therefore, is the dearth of studies that focus on social work students, their adverse childhood experiences and the positive growth that could emerge from their personal histories. The researcher's main assumptions therefore were that students have endured ACEs and that there were concerted links between their having endured ACEs and 
the learning context. Consequently the main research question is: What are the perceptions and experiences of social work students regarding their coping with adverse childhood experiences in the context of social work teaching and learning?

\section{COPING WITH ADVERSE CHILDHOOD EXPERIENCES}

Coping refers to the mental and physical action used to process the internal and external requirements of stressful incidents (Taylor and Stanton, 2007; Folkman and Moskowitz, 2004). Coping will be discussed with reference to specific promotive and protective factors that determine the way in which individuals cope, as well as the emergence of resilience and PTG as positive coping outcomes.

\section{Promotive and protective factors}

Promotive and protective factors are significant when exploring the strengths and competencies that people derive from adverse circumstances. These factors are also vital to determine the elements that are critical for building strengths and positive outcomes. Promotive and protective factors act as mediators between stressors and endurance that may inhibit stress and anxiety and/or safeguard the person from the stressful event. The possible risks associated with adverse experiences may thus be reduced.

Fergus and Zimmerman (2005:299) describe promotive factors as being either "assets or resources". Assets are characteristics within the person and resources are external to the person. Greene and Greene (2009) identified protective factors as the characteristics and traits of a person or in their social context that increase the likelihood of positive outcomes from adverse experiences. There are three core protective or promotive factors, namely: intra-personal, family, and community and environmental factors (Greene and Greene, 2009; Fergus and Zimmerman, 2005; Saleebey, 2002; Van Breda, 2001).

These factors are interrelated as they build upon one another starting with intra-personal factors, which are enveloped by family and then community and environmental factors as further protective layers (Armstrong, Birnie-Lefcovitch and Ungar, 2005; Saleebey, 2002). These promotive and protective factors are further clarified below:

Intra-personal factors:

- attributes: birth order, gender, temperament, and personality traits

- Social skills: self-esteem and mastery beliefs (self-efficacy)

- Personal Coping style: physical and cognitive plans, cumulative skills from adversity

Family factors:

- Family cohesion: nurturing structure and order

- Family perspicuity: family expression and communication

- Family unity: positive interactions

- Parental consistency: parental agreements regarding disciplining and caring 
Community and environmental factors:

- Ability to access resources and assistance: adult mentors, peer groups, extended family

These factors showcase the multitude of characteristics, abilities and resources that are vital for developing positive coping behaviours. In the focus on intra-personal factors, much has been written on emotional intelligence as a protective factor (Kinman and Grant, 2011). With particular reference to social work students, other significant qualities are reflective abilities, empathy and social skills. However, these qualities would mean that students would require emotional intelligence and cognitive abilities. These, in turn, would presuppose promotive and protective factors.

A significant construct that emerges from promotive and protective factors is the notion of social support. Social support acts as a promotive factor (external to the person) for coping and developing resilience (Ozbay, Fitterling, Charney, and Southwick, 2008; Pinkerton and Dolan, 2007). The definitions of social support explicate the who (provider) and the what (action and assistance) of support. In the first aspect, social support is described as being contextualised within sources of casual (everyday) support provided to others by family, friends, neighbours and peers characterised by non-payment and informal arrangements (Pinkerton and Dolan, 2007; Armstrong et al., 2005). In confirming the source of support, Wilks and Spivey (2010:278) contend that social support "is a broad concept covering the availability of significant others". Family and extended family represent the most powerful social support structure for people (Taylor, 2010). Social support from the extended family has been shown to contribute to coping and resilience of both parents and children, especially those enduring adverse circumstances. Extended family support is vital in two areas especially: the proffering of emotional support and upholding structure and harmony in the home (Taylor, 2010).

In terms of the what, Gottlieb confirmed the action of supporters, defining social support as "verbal and non-verbal information or advice, tangible aid, or action that is proffered by social intimates or inferred by their presence and has beneficial emotional or behavioural effects on the recipients" (cited in Armstrong et al., 2005:271). Support is characterised in practical terms regarding the type of support (the what) that is provided to an individual who requires it. Having endured adverse circumstances, and possibly received requisite support, the outcome of the process of coping is identified as resilience.

\section{Resilience}

In this study, resilience is viewed as an outcome signalling the positive overcoming of adversity. Masten, Best and Garmezy (1990:425) contributed to the initial definition that spearheaded others. They defined resilience as "the process of, capacity for, or outcome of successful adaptation despite challenging or threatening circumstances”. Other definitions that followed focused on the central themes of adaptation and adverse circumstances. For example, Luthar, Cicchetti and Becker (2000:543) defined resilience as "a dynamic process 
encompassing positive adaptation within the context of significant adversity". Coombes and Anderson (2000:287) refer to resilience as having the "capacity for successful adaptation, positive functioning and competence" in the face of "high risk status, chronic stress or prolonged or severe trauma". Vital to resilience is resistance, in particular, resistance to 'psychosocial risk' (Rutter, 1999:119). Saleebey (2002:11) linked resilience to personal skill development, by referring to resilience "as a process - the continuing growth and articulation of capacities, knowledge, insight, and virtues derived through meeting the demands and challenges of one's world, however chastening". Salient features of resilience therefore appear to include the following:

- Resilience emerges through a process of coping

- The individual should have certain skills in resisting adversity

- The person must have overcome adversity

- The person has managed to emerge relatively unscathed (in the recognition that there are often residual after-effects) (Kinman and Grant, 2011; Shepherd, Reynolds and Moran, 2010; Greene and Greene, 2009; Saleebey, 2002).

Pre-requisite conditions for resilience should be the existence of adverse circumstances and a positive outcome regardless of circumstances (Luthar et al., 2000). A person develops resilience through an interactive and dynamic process during which an adverse event or circumstance triggers the interrelation between protective (such as inner resources, family and peer networks, and community resources) and risk factors (such as poverty, poor parental and family relationships and interactions) that a person may possess or be surrounded with. Protective factors contribute to resilience, whereas risk factors make people more vulnerable (Olsson, Bond, Burns, Vella-Brodrick and Sawyer, 2003). The positive outcome would be resilience. In other words, a person cannot become or know that they are resilient without having gone through difficulties and struggles, which also attests to coping. A child's resilience is fostered by the standard of parental care and the child's adeptness in adjusting to stressful situations (Armstrong et al., 2005; Masten, 2001). Each person has different levels of protective and risk factors and these influence the eventual outcome of experiencing adversity.

\section{Posttraumatic growth}

PTG is defined as the phenomenon of personal growth and development that results from the struggle with significant childhood challenges (Tedeschi and Calhoun, 2004). The concept of PTG was developed through research by Tedeschi and Calhoun and founded on the existentialist philosophies of Danish philosopher Søren Kierkegaard (1813-1855) and German philosopher Friedrich Nietzche (1844-1900) (Anderson, Davis and Havig, 2011; Zoellner and Maercker, 2006). Five domains have been identified as representative of PTG through the research by Taku, Calhoun, Cann and Tedeschi in 2008 (Rodgers, 2014). These are: (1) Renewed appreciation of life; (2) New possibilities; (3) Enhanced personal strength; (4) Improved relationships with others; and (5) Spiritual change. 
The literature on coping and resilience has related these two constructs as one being the process through which a person endures a particular experience (coping) and the other the positive outcome of this process or experience (resilience). However PTG also emerges from coping and resilience that reflect the personal growth that can occur after an adverse experience.

\section{RESEARCH METHODOLOGY}

The study was focused on the meaning people ascribe to their experiences and was entirely dependent on obtaining personal accounts. Therefore, the qualitative research approach was deemed appropriate as a methodology as was the selection of the case study design. Case study design focuses on the study of an issue (for example, adverse childhood experiences) explored through one or more cases (for example, the case is social work teaching and learning) within a bounded system which could indicate the context or setting (for example, the third year social work class in a module called family well-being within one university setting) (Creswell, 2013; Khan and Van Wynsberghe, 2008). For this study, data was collected from third-year social work students where the researcher was also the lecturer. Two data collection methods were used:

1. Reflexive assignments in a specific third-year social work module, where firstly volunteer sampling elicited 37 assignments, and secondly purposive sampling to reduce to 20 assignments. The latter was based on inclusion criteria, for example, varied experiences that could relate to ACEs that would link to the objectives of the study. The reflexive exercises formed part of the formative tasks of all students in the module and focused on intervention and family well-being. Students were required to reflect on 7 questions that focused on the role and influence of their own childhood experiences in their professional learning context. The dual role of the researcher was openly discussed especially regarding pressure to participate and perceived negative consequences if not participating.

2. Individual interviews with further purposive sampling of 10 student participants (derived from the sample of reflexive assignments). The inclusion criteria consisted of participants describing at least two elements in the definition of ACEs. The researcher looked for a variation of incidents as explicated in the definition. The researcher was able to reach all participants that were identified to be included as there was no missing or nonresponsive participants. Through these interviews, the researcher was able to listen to how students described their experiences and to perceive their emotional distress as they were frequently overcome with emotion. Debriefing services were offered to all participants.

Thematic analysis was used to gain understanding of the patterns, forms and configurations of the data sets (reflexive assignments and student interviews) (Babbie, 2014; Creswell, 2013; De Vos, 2007). The data were analysed in accordance with the steps in within-case analysis (Creswell, 2013). A deductive approach or a priori themes was used as this approach delineated categories and themes that emerge from "our prior theoretical understanding of whatever phenomenon we are studying" (Bernard and Ryan, 2010:55). In 
practice, data analysis began by reading the data until categories, sub-themes and themes emerged in relation to common patterns and associations with respect to each data set but also to PTG. The researcher selected four validation strategies to authenticate the process of data collection and data analysis, namely, triangulation; member checking; thick, rich descriptions; and researcher reflexivity (Creswell, 2013; Babbie and Mouton, 2007).

Ethics clearance was obtained from the tertiary institution and conformed to ethics guidelines to research, for example, preventing harm to the participants, informed consent and preparation for the evocative nature of the study, protecting the privacy of the participants, and protection from researcher / lecturer influence (Babbie and Mouton, 2007; Strydom, 2007).

\section{POSTTRAUMATIC GROWTH AS MAIN THEME AND FINDING}

The picture that emerged from the initial data analysis was the strong link with the domains of PTG which there represents the main theme. The main theme encompasses participants' reflections on the ways in which both their positive and negative experiences had contributed to what they had learnt about themselves. The sub-themes are underpinned by categories of data indicating the depth of each one (Table 1).

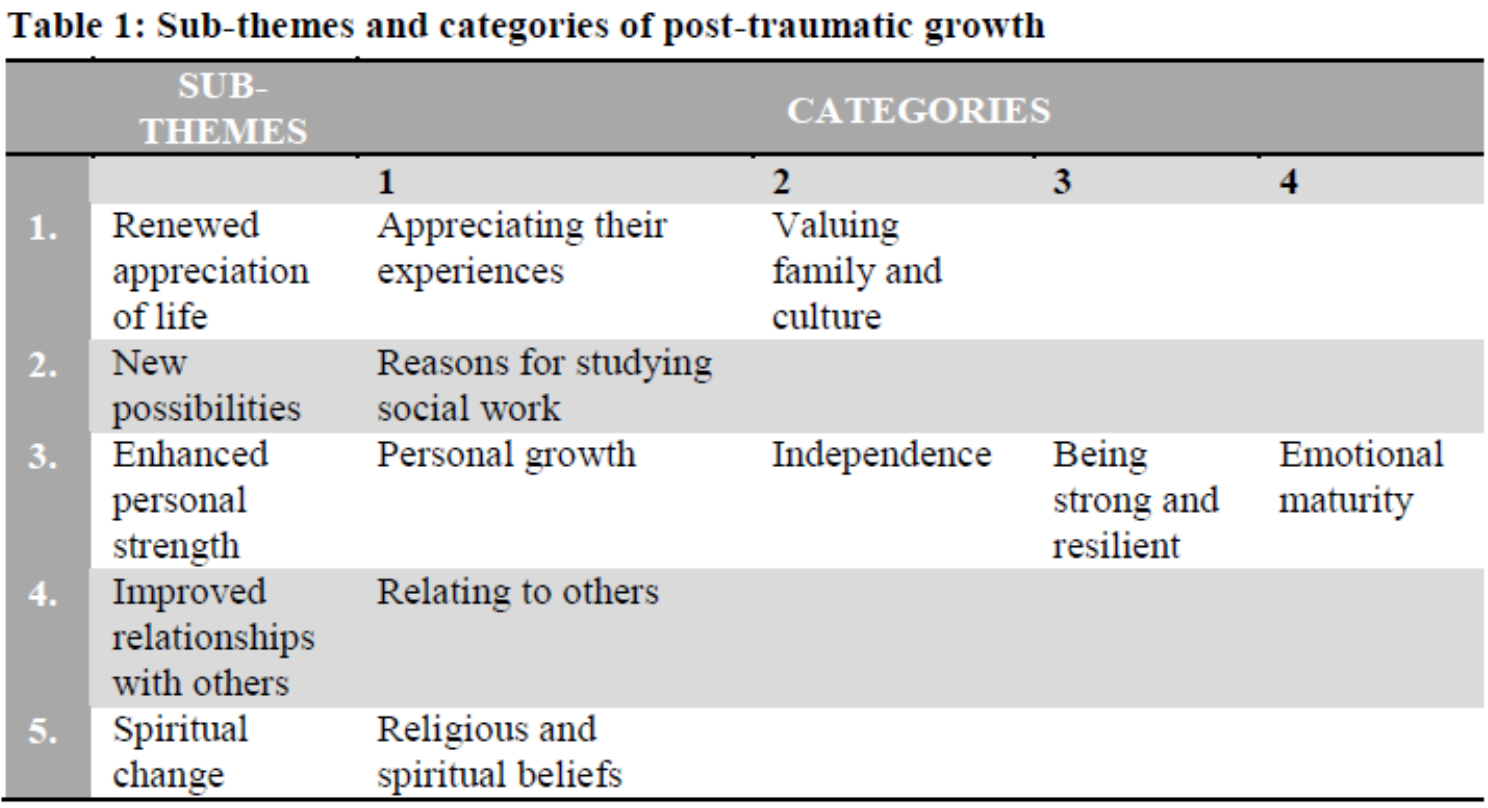

Table 1 clarifies the five sub-themes and nine categories that emerged from the main theme of posttraumatic growth. The following discussion represents the findings relating to the perceived posttraumatic growth of participants.

\section{Renewed appreciation for life}

A common feature in PTG is a renewed appreciation of life and what one has as well as an increased awareness of what is important (Tedeschi and Calhoun, 2004). Two sub-themes 
reflect the domain, for example, participants' appreciating their experiences and valuing their families and cultures.

Appreciating their experiences: Participants divulged their overall appreciation and acknowledgement of their experiences that enabled them to appreciate their own experiences juxtaposed with those of others and how these influence their behaviour, beliefs and future:

- As a person I became aware of other people's problems and similar situations and I would understand their situations and will not be judgemental or discriminating towards these people.

- The experiences that I was faced with growing up actually made me stronger and a better person. Inow know what is most important in my life...

Participants illustrated their positiveness (post ACEs) in their interaction and engagement with others, externalising their positive social values and beliefs. Studies confirm that learned efficacy and personal beliefs and values (such as self-worth, judgment, dependability, credibility and self-regulation) were related to personal adjustment following adverse experiences (Lai, Zauszniewski, Tang, Hou, Su and Lai, 2014; Turner, Goodin and Lokey, 2012). People who have a receptive cognitive style will be enabled to be accepting, tolerant, and non-judgmental (Tedeschi, 1999). According to cited literature, to initiate and sustain these social values, it would presuppose that the individual has achieved a measure of self-efficacy and self-belief after ACEs. Certainly it appears that some participants could achieve this (supported by their training in social work).

Valuing family and culture: Participants believed that family and culture should be valued in terms of relationship building, as sources of support and communication, and through their family they became more enlightened about their heritage and language. The following are extracts from participants' narratives to corroborate the category of valuing family and culture:

- The positive incidents installed knowledge to speak and write Xhosa fluently.

- Due to the family support I received during my early childhood years, I believe that family is the most important source of support and communication.

- ...she [referring to her mother] started selling everything in the house and that's where I actually saw that she loved us and she loved me because then I started seeing I realised that if there's nothing to eat, she would go sleep without eating and that's where I actually saw that she cared. She maybe wasn't able to show it in the beginning...

Despite the often negative role that family had played in ACEs, participants nevertheless viewed family and culture as vital to their recovery. In terms of family support, research results suggest that positive support from families was related to fewer trauma-related symptoms, especially in non-sexual abuse, which contributed to healing and PTG (Walsh, 2007, 2006; Bal, Crombez, Van Oost and Debourdeaudhuij, 2003). Research also found a 
strong link between socio-cultural support and the assuaging of the extremes of trauma (Park, Kitayama, Karasawa, Curhan, Markus, Kawakami, Miyamoto, Love, Coe and Ryff, 2013; Ungar, 2008; Elliot and Urquiza, 2006). This finding also underscored the fourth domain (improved relationships with others) of PTG. Literature listed has acknowledged the significant role of family and culture in life's lessons and for achieving PTG.

\section{New possibilities}

New possibilities presupposes that persons can visualise and consider that there is hope for their future for example taking a different path (Tedeschi and Calhoun, 2004) or taking the form of embarking on a study programme in social work for example.

Reasons for studying social work: people choose careers for different reasons, but for social work, more often than not, there are deeply personal motivating reasons. The following narratives show the links between social work and the personal circumstances of participants:

- In a way it influenced me in the manner which pushed me to study social work because $\underline{I}$ want to assist families going through similar circumstances which I did.

- Like that really I think it was a blessing in disguise for me to experience that because my experience also contributed a lot to me choosing to be... a social worker because I thought okay if I can be a social worker then maybe I can help other children not to experience what I've been through

- But what I'm striving for, firstly I chose to do social work here at the varsity in order to empower those children that undergo what I went through and I also want to make my mother proud of having me

Positive outcomes are also viewed through the ways that people use to make meaning of childhood adversity, such as by taking action; wanting to enlighten others; to obtain justice; and possibly to prevent recurrences of similar incidents (Tedeschi, 1999). Stevens, Moriarty, Manthorpe, Hussein, Sharpe, Orme, Mcyntyre, Cavanagh, Green-Lister and Crisp (2012) assert that, to advance social work education and the profession, it is important to understand the reasons compelling people to become social workers. Research findings confirm that the dominant reasons for pursuing social work are personal ones (Perry, 2003), and those relating to family (Buchbinder, 2007; Sellers and Hunter, 2005).

\section{Enhanced personal strength}

Personal strength reflect the capacity of individuals to respond appropriately (within context) in terms of the means of achieving levels of positive adjustment after traumatic experiences (Westphal, Seivert and Bonanno, 2010). This capacity underscores the inner motivation for change, adaptation and transformation that is an integral aspect of PTG (Anderson et al., 2011; Zoellner and Maercker, 2006). This sub-theme and three categories also relate to the intra-personal attributes (protective/promotive factors) of the individual. 
Personal growth: Personal growth was illustrated by a range of behaviours and insights in relation to the negative experiences some of the examples are cited below:

- $\quad$ So when it [adverse experience] happened I had to be rational, I had to think straight and I'm not the person that blames people for what I did....

- These experiences, instead of making me want to seek for attention in other places, help me to put all my frustration and hurt into my school work and became a good student.

- I have learnt that the experiences that have occurred in my life were my lessons about how harsh life can be and they made me strong as I am today.

- This incident also taught me to adapt very easily to changes and learn to accept things that I cannot change as well as to make the best out of every situation.

The narratives disclosed the striving of participants to act and behave appropriately despite their adverse circumstances in terms of life's lessons. The findings showed the personal growth achieved through coming to know them better and rethinking their familiar perceptions and responses to familiar circumstances. Thus PTG is initiated from within the individual and emerges from a process of meaning-making (cognitive processing) and gaining self-knowledge (becoming self-aware) (Anderson et al., 2011; Joseph, 2009; Tedeschi and Calhoun, 2004).

Independence: Students' autonomy was typified by the sense of doing things on their own and being capable of handling most things. The following extracts provide support for the category of independence:

- My experiences taught me to [be] more appreciative and to be an independent person.

- Even though the fact that I had to take care of myself during my teen years, I have realized that the experience has made me an independent person. I have learnt to depend on myself, work hard because there is no one else who will do for me but myself.

- I developed independence in such a way that I did not depend / have to do what my parents do, but I knew that I had to make the choices that I think are right for me.

The findings show the participants' disclosing their independence underpinned by their sense of self-efficacy (mastery) that increased their self-confidence. The literature validates these findings. Children forced into adult responsibilities do learn particular coping skills (self-efficacy) enabling them to be mature, resourceful and responsible (East, 2010; Hooper, Marotta and Lantheir, 2008).

Being strong and resilient: Strength and resilience were cited several times by participants, as seen by the following examples:

- These childhood experiences helped me to be strong as a person and learn not to depend on other people but my family because they are always there for me.

- ...to be resilient in the face of challenges. 
- It provided me with the resilience to overcome all the negative circumstances/incidents I experienced in my later childhood.

- I have learned that no matter what you go through in life you have to rise above your circumstances in order to be a success.

These findings showed that the participants did have the resilience to endure ACEs and have motivation and hope for the future. Resilience enabled participants to develop the strength and self-confidence to persevere and be assertive. This illustrated PTG in the sense that resilience enables an individual to overcome and to bounce back from negative and often traumatic incidents and, in so doing, avert, diminish or prevail (McDougall, 2011; Mohaupt, 2008). Research confirms the significant degrees of resilience that emerged as a consequence of enduring childhood adversity (Seery, Holman and Silver, 2010; Bonanno and Mancini, 2008). Resilience is differentiated from PTG in that resilience is viewed as the means to achieve PTG (Westphal and Bonanno, 2007).

Emotional maturity: Participants learnt that positive outcomes should be in terms of their maturing feelings and emotions. Illustrations of the emotional maturity of student participants are as follows:

- I have learned that I need to speak about my negative incidents to someone more often so that I can find healing and closure and also to rebuild myself in terms of my self- worth, confidence, trust and love for myself.

- I learned that I am a human being, a person with feelings and emotions, and I must stop blocking my emotions with fears and hatred or anger.

- I have learnt that once you have discovered who you are, no one can take that away from you, no matter what they do.

These narratives revealed the emotional and cognitive realisations of participants after their personal experiences. Emotional maturity involves a difficult process for any individual. Research has revealed personality, mindfulness practice (self-awareness) and spirituality to be predictors of maturity or growth (Jong, 2013; Lloyd, 2012) that reflect a healthy balance between posttraumatic stress and growth (Joseph and Lindley, 2008). Klever (2009) also emphasised that PTG is made possible through self-acceptance, personal well-being and environmental conditions. Achieving emotional maturity is not so much an end but rather a process (a journey) of self-discovery. The literature discussed has explicated the key aspects that appropriately focus on the self. Therefore self-awareness and mindfulness are significant drivers on this journey. These findings could also indicate the first (renewed appreciation of life) and second (new possibilities) domains of PTG reflecting the beginnings of renewed appreciation of life and through this can envision new possibilities for the future. 


\section{Improved relationships with others}

PTG can also encompass more intimate and meaningful relationships with others and an increased ability therefore to relate to others despite having poor role models in this human endeavour (Tedeschi and Calhoun, 2004). This sub-theme shows one category:

Relating to others: Participants reported that despite their negative experiences of family relationships, they nonetheless developed into caring, loving and compassionate persons in their relationships with others. The following excerpts attest to these:

- Throughout my childhood I have acquired that I am strong young woman who is able to interact with people very well.

- I learnt to have an open relationship with my children so that they have the confidence to approach me with any problem that they encounter in life.

- I learnt how to socialise with other people as the way of getting different views about the world and used socialisation as a means of gathering the information that I don't have.

Findings reveal that participants, despite their difficult relationships they had experienced with others, could still find the motivation to positively engage with other people. Through this, they had gained positive communication and relationship building skills. The ability to relate positively to others is also a hallmark of social work assessment and intervention (Kirst-Ashman and Hull, 2015).

\section{Spiritual change}

Growth in spiritual, religious and existential aspects in terms of post-traumatic experiences is also a common occurrence, although some people may only undertake engagement with existential questions which then is also considered growth (Shaw, Joseph and Linley, 2005; Tedeschi and Calhoun, 2004). The following category reflects spiritual change and growth.

Religious and spiritual beliefs: Participants believed that life should be lived in accordance with religious beliefs and participants acknowledged their belief in God as well as a sense of belonging in their church. Participants' narratives regarding their religious beliefs are asfollows:

- My childhood experiences shaped the person I am today and being raised in such a religious family, I still belief in faith and that God can get us through any situation faced.

- I also discovered that I have a real stable relationship with God - I pray a lot, something I never did as a young child.

- I changed as a person because I started going back to church where I learnt more about forgiveness.

Participants' sustained and renewed religious beliefs and faith came through repeatedly. Research results also show that religion is a significant conduit for meaning-making following trauma and loss (called spiritual coping) that is associated with healthy outcomes (Cotton, Zebracki, Rosenthal, Tsevat and Drotar, 2006; Park, 2005). The fifth domain 
(spiritual change) of PTG involves openness to spirituality and religious beliefs as well as spiritual change (Rodgers, 2014; Anderson et al., 2011). Spirituality and religion are also identified as key indicators in PTG (Prati and Pietrantoni, 2009; Cadell, Regehr and Hemsworth, 2003). Religious beliefs emerged again as one of life's lessons for participants, and this, in accordance with stated literature, is an important dimension of PTG.

\section{DISCUSSION AND CONCLUSIONS}

Having endured ACEs, the findings reflected that participants had coped with their experiences and had emerged with positive characteristics and beliefs. Coping was a precursor to developing resilience and PTG. Posttraumatic growth exemplified the positive outcomes that participants could discern from having endured childhood adversity.

The five domains of PTG and their relationship to the findings illustrated the extent to which the findings can be identified as being PTG. In terms of renewed appreciation of life, participants' appreciation of their experiences and valuing of family and culture (heritage and language) show that they possess the energy to acknowledge their life and to view their world differently. The second sub-theme (new possibilities) reflected the motivation for wanting to become a social worker which was inextricably linked to participants' challenging childhoods which then motivated them to enter a profession like social work. The strongest evidence resorted under the third sub-theme of enhanced personal strength which showcased their personal growth, independence, strength and resilience, as well as emotional maturity that emerged from enduring ACEs. Relating to others (fourth subtheme) elucidated their abilities to relate to others despite their often negative experiences with mostly family members. Spiritual growth and change (fifth sub-theme) also represented participants' strong spiritual and religious beliefs and the dominant role that these beliefs play in their lives. The findings overall also substantiate the second domain for seeing new possibilities which speak to the prospects of a positive future for participants in the context of their adverse childhood experiences.

The conclusion is that participants have derived constructive outcomes and growth from their ACEs. The implication is that PTG must be understood alongside the effects of ACEs on participants to fully comprehend the consequences of ACEs in terms of being 'two sides of the same coin'. This means that many social work students show resilience in the face of adversity, but also continue to struggle with the effects of ACEs.

Resilience has four features identified as being process, proficiencies, prevailing, and positive outcomes (Kinman and Grant, 2011; Shepherd et al., 2010). These features also underscore the process of coping. Through the cited literature the relationship between the process of coping and resilience was rather nebulous. In this study, the emergence of PTG and its perceived relationship with coping and resilience, revealed their very close associations. PTG appears to be a long-term outcome to the process of coping that goes beyond resilience. Coping, resilience and PTG can be vital areas for social work education and practice. Rodgers (2014) confirms that it is incumbent on social work education to 
appropriately embed coping and PTG in the curriculum and to expose students to coping responses for assessment and intervention.

Despite the overwhelming evidence of PTG, Wortman (2004) issued strong criticism of PTG. Her overall concern was that PTG would decrease vigilance for the severe effects of social issues and may disregard the role of social conditions in the person's adverse experiences as the focus is too individualised. Her concerns therefore mirror Gray's (2011) critique regarding the focus of strengths perspectives. Interventions should, therefore, be more holistic regarding this preponderance on individualistic perspectives.

\section{RECOMMENDATIONS FOR SOCIAL WORK EDUCATION AND PRACTICE}

The role of coping and resilience in social work is vital because it would be of benefit not only to social work teaching and learning but also to social work practice. The implications of the findings are that PTG should be considered by social work lecturers in curriculum planning regarding the exploring of professional use of self and self-awareness through, for example, mindfulness practices. Mindfulness in the classroom is a cognitive activity for raising students' awareness of their internal and external lenses that would enable them to pay unencumbered attention to their emotions and to the various viewpoints in the class as the learning process unfolds (Coholic, 2011; Napoli and Bonifas, 2011). The outcomes of mindfulness include self-acceptance, trust, non-judgementalism and self-awareness (Birnbaum and Birnbaum, 2008). The suggestion is an important one as it reflects and acknowledges the personal struggles of students especially in the social work learning context.

Posttraumatic growth has positive implications for social work practice. Firstly, from a strengths perspective, there is the realisation and affirmation that people can grow and develop from previous traumatic and negative experiences. Secondly, that the effects of ACEs need not necessarily be so dire that growth is unlikely. This implies that in social work practice hope can be sustained both for the client and for the social worker. This further implies that PTG can be used in a framework for assessment and intervention in micro and mezzo practices, especially from a strengths perspective, and which should also be embedded in teaching and learning.

\section{LIMITATIONS OF THE STUDY}

The study was conducted with participants at a specific university and therefore the findings are unique to the context of this setting and can therefore not be generalised to other contexts. This is not unusual because the importance of context is emphasised in qualitative research studies and case study designs. The findings can provide insight for social work programmes where students' profiles are similar. 


\section{References}

Anderson, K., Davis, F. and Havig, K. (2011). "Adult Daughters of Battered Women: Recovery and Posttraumatic Growth Following Childhood Adversity" Families in Society: The Journal of Contemporary Social Services 92(2):154-160.

Armstrong, M., Birnie-Lefcovitch, S. and Ungar, M. (2005). "Pathways between Social Support, Family Wellbeing, Quality of Parenting, and Child Resilience: What We Know" Journal of Child and Family Studies 14:269-281.

Babbie, E. (2014). The Basics of Social Research California, USA: Cengage Learning, Sixth Edition.

Babbie, E. and Mouton, J. (2007). The Practice of Social Research Cape Town: Oxford University Press, SA Edition.

Bal, S., Crombez, G., Van Oost, P. and Debourdeaudhuij, I. (2003). "The Role of Social Support in Well-being with Self-reported Stressful Events in Adolescents" Child Abuse and Neglect 27(12):1377-1395.

Bernard, H. and Ryan, G. (2010). Analyzing Qualitative Data: Systematic Approaches California, USA: Sage.

Birnbaum, L. and Birnbaum, A. (2008). "Mindful Social Work: From Theory to Practice" Journal of Religion and Spirituality in Social Work: Social Thought 27(1-2):87-102.

Bonanno, G. and Mancini, A. (2008). "The Human Capacity to Thrive in the Face of Potential Trauma” Pediatrics 121(2):369-375.

Buchbinder, E. (2007). "Being a Social Worker as an Existential Commitment: From Vulnerability to Meaningful Purpose" The Humanistic Psychologist 35(2):161-174.

Cadell, S., Regehr, C. and Hemsworth, D. (2003). "Factors Contributing to Posttraumatic Growth: A Proposed Structural Equation Model" American Journal of Orthopsychiatry 73(3):279-287.

Carelse, S. and Dykes, G. (2013). "Integration of Theory and Practice in Social Work: Challenges and Triumphs" Social Work/Maatskaplike Werk 49(2):165-182.

Coholic, D. (2011). "Exploring the Feasibility and Benefits of Arts-based Mindfulnessbased Practices with Young People in Need: Aiming to Improve Aspects of Self-awareness and Resilience" Child Youth Care Forum 40(4):303-317.

Coombes, K. and Anderson, R. (2000). "The Impact of Family of Origin on Social Workers from Alcoholic Families" Clinical Social Work Journal 28(3):281-301. 
Cotton, S., Zebracki, K., Rosenthal, S., Tsevat, J. and Drotar, D. (2006). "Religion/spirituality and Adolescent Health Outcomes: A Review" Journal of Adolescent Health 38(4):472-480.

Creswell, J. (2013). Qualitative Inquiry and Research Design: Choosing among Five Approaches Thousand Oaks, CA: Sage, Third Edition.

De Vos, A. (2007). "Qualitative Data Analysis and Interpretation” in De Vos, A., Strydom, H., Fouche, C. and Delport, C. (Eds.). Research at Grass Roots: For the Social Sciences and Human Service Professions Pretoria: Van Schaik, Third Edition, 333-354.

Dube, S., Felitti, V., Dong, M., Giles, W. and Anda, R. (2003). "The Impact of Adverse Childhood Experiences on Health Problems: Evidence from Four Birth Cohorts Dating Back to 1900" Preventive Medicine 37(3):268-277.

Dykes, G. (2014). An Enquiry into the Role of Adverse Childhood Experiences on Teaching and Learning in Social Work (Unpublished Doctoral Thesis) Stellenbosch: University of Stellenbosch, Social Work Department.

East, P. (2010). “Children's Provision of Family Caregiving: Benefit or Burden?” Child Development Perspectives 4(1):55-61.

Fergus, S. and Zimmerman, M. (2005). "Adolescent Resilience: A Framework for Understanding Healthy Development in the Face of Risk" Annual Review of Public Health 26:399-419.

Folkman, S. and Moskowitz, J. (2004). "Coping: Pitfalls and Promise" Clinical Review of Psychology 55:745-774.

Gibbons, S., Murphy, D. and Joseph, S. (2011). "Countertransference and Positive Growth in Social Workers" Journal of Social Work Practice: Psychotherapeutic Approaches in Health, Welfare and the Community 25(1):17-30.

Gray, M. (2011). "Back to Basics: A Critique of the Strengths Perspective in Social Work" Families in Society: The Journal of Contemporary Social Services 92(1):5-11.

Greene, R. and Greene, D. (2009). "Resilience in the Face of Disasters: Bridging Microand Macro-perspectives" Journal of Human Behavior in the Social Environment 19:10101024 .

Hooper, L., Marotta, S. and Lantheir, R. (2008). "Predictors of Growth and Distress following Childhood Parentification: A Retrospective Exploratory Study” Journal of Child and Family Studies 17(5):693-705. 
Jong, H. (2013). "Mindfulness and Spirituality as Predictors of Personal Maturity beyond the Influence of Personality Traits" Mental Health, Religion and Culture 16(1):38-57.

Joseph, S. (2009). "Growth Following Adversity: Positive Psychological Perspectives on Posttraumatic Stress” Psychological Topics 18(2):335-344.

Joseph, S. and Linley, P. (2008). "Positive Psychological Perspective on Psychological Stress: An Integrative Psychosocial Framework" in Joseph. S. and Linley. P. (Eds.). Trauma, Recovery, and Growth: Positive Psychological Perspectives on Posttraumatic Stress New Jersey: John Wiley, 3-20.

Khan, S. and Van Wynsberghe, R. (2008). "Cultivating the Undermined: Cross-case Analysis as Knowledge Mobilization” Forum: Qualitative Social Research 9(1): Art. 34.

Kinman, G. and Grant, L. (2011). "Exploring Stress Resilience in Training Social Workers: The Role of Emotional and Social Competencies" British Journal of Social Work 41(2):261-275.

Kirst-Ashman, K. and Hull, G. (2015). Empowerment Series: Understanding Generalist Practice Connecticut, USA: Cengage Learning, Seventh Edition.

Klever, P. (2009). "Goal Direction and Effectiveness, Emotional Maturity, and Nuclear Family Functioning” Journal of Marital and Family Therapy 35(3):308-324.

Lai, C., Zauszniewski, J., Tang, T., Hou, S., Su, S. and Lai, P. (2014). "Personal Beliefs, Learned Resourcefulness, and Adaptive Functioning in Depressed Adults" Journal of Psychiatric and Mental Health Nursing 21(3):280-287.

Lloyd, J. (2012). "Psychological Type and the Religious Quest for Wisdom and Maturity" Mental Health, Religion and Culture 15(9):837-847.

Luthar, S., Cicchetti, D. and Becker, B. (2000). "The Construct of Resilience: A Critical Evaluation and Guidelines for Future Work" Child Development 71(3):543-562.

Masten, A. (2001). "Ordinary Magic: Resilience Processes in Development" American Psychologist 56(3):227-238.

Masten, A., Best, K. and Garmezy, N. (1990). "Resilience and Development: Contributions from the Study of Children who Overcome Adversity" Development and Psychopathology 2:425-444.

McMillen, J. (1999). "Better For It: How People Benefit from Adversity" Social Work 44(5):455-467. 
Napoli, M. and Bonifas, R. (2011). "From Theory Towards Empathic Self-care: Creating a Mindful Classroom for Social Work Students" Social Work Education 30(6):635-649.

Olsson, C., Bond, L., Burns, J., Vella-Brodrick, D. and Sawyer, S. (2003). "Adolescent Resilience: A Concept Analysis" Journal of Adolescence 26(1):1-11.

Ozbay, F., Fitterling, H., Charney, D. and Southwick, S. (2008). "Social Support and Resilience to Stress Across the Life Span: A Neurologic Framework" Current Psychiatric Report 10(4):304-310.

Park, C. (2005). "Religion as a Meaning-making Framework in Coping with Life Stress" Journal of Social Issues 61(4):707-729.

Park, J., Kitayama, S., Karasawa, M., Curhan, K., Markus, H., Kawakami, N., Miyamoto, Y., Love, G., Coe, C. and Ryff, C. (2013). "Clarifying the Links between Social Support and Health: Culture, Stress and Neuroticism Matter” Journal of Health Psychology 18(2):226235 .

Perry, R. (2003). "Who Wants to Work with the Poor and Homeless"? Journal of Social Work Education 39(2):321-342.

Petersen, S. (2010). Challenges of Integrating Theory and Practice in Social Work Teaching and Learning (Unpublished Master's Thesis) Cape Town: University of the Western Cape, Social Work Department.

Pinkerton, J. and Dolan, P. (2007). "Family Support, Social Capital, Resilience and Adolescent Coping" Child and Family Social Work 12(3):219-228.

Prati, G. and Pietrantoni, L. (2009). "Optimism, Social Support, and Coping Strategies as Factors Contributing to Posttraumatic Growth: A Meta-analysis" Journal of Loss and Trauma: International Perspectives on Stress and Coping 14(5):364-388.

Rodgers, S. (2014). "Posttraumatic Growth" Encyclopedia of Social Work. doi: 10.1093/ acrefore/9780199975839.013.1001 (Accessed on 28/3/2015).

Saleebey, D. (2002). The Strengths Perspective in Social Work Practice Boston: Allyn and Bacon, Third Edition.

Seery, M., Holman, E. and Silver, R. (2010). "Whatever Does Not Kill Us: Cumulative Lifetime Adversity, Vulnerability, and Resilience" Journal of Personality and Social Pathology 99(6):1025-1041. 
Sellers, S. and Hunter, A. (2005). "Private Pain, Public Choices: Influence of Problems in the Family of Origin on Career Choices among a Cohort of MSW Students" Social Work Education 24(8):869-881.

Shaw, A., Joseph, S. and Linley, P. (2005). "Religion, Spirituality, and Posttraumatic Growth: A Systematic Review" Mental Health, Religion and Culture 8(1):1-11.

Shepherd, C., Reynolds, F. and Moran, J. (2010). "They're Battle Scars, I Wear Them Well': A Phenomenological Exploration of Young Women's Experiences of Building Resilience following Adversity in Adolescence" Journal of Youth Studies 13(3):273-290.

Stevens, M., Moriarty, J., Manthorpe, J., Hussein, S., Sharpe, E., Orme, J., Mcyntyre, G., Cavanagh, K., Creen-Lister, P. and Crisp, B. (2012). "Helping Others or a Rewarding Career? Investigating Student Motivations to Train as Social Workers in England" Journal of Social Work 12(1):16-36.

Strydom, H. (2007). "Ethical Aspects in the Social Sciences and Human Service Professions" in De Vos, A., Strydom, H., Fouche, C. and Delport, C. (Eds.). Research at Grassroots: For the Social Sciences and Human Service Professions Pretoria: Van Schaik, Third Edition, 56-70.

Taku, K., Calhoun, L., Tedeschi, R., Gil-Rivas, V., Kilmer, R. and Cann, A. (2007). "Examining Posttraumatic Growth among Japanese University Students" Anxiety, Stress and Coping: An International Journal 20(4):353-367.

Taylor, R. (2010). "Risk and Resilience in Low-income African American Families: Moderating Effects of Kinship Social Support" Cultural Diversity and Ethnic Minority Psychology 16(3):344-351.

Taylor, S. and Stanton, A. (2007). "Coping Resources, Coping Processes, and Mental Health” Annual Review of Clinical Psychology 3:377-401.

Tedeschi, R. (1999). "Violence Transformed: Posttraumatic Growth in Survivors and Their Societies" Aggression and Violent Behavior 4(3):319-341.

Tedeschi, R. and Calhoun, L. (2004). "Posttraumatic Growth: Conceptual Foundations and Empirical Evidence” Psychological Inquiry 15(1):1-18.

Turner, J., Goodin, J. and Lokey, C. (2012). "Exploring the Roles of Emotions, Motivations, Self-efficacy, and Secondary Control Following Unexpected Life Events" Journal of Adult Development 19(4):215-227.

Ungar, M. (2008). "Resilience across Cultures" British Journal of Social Work 38(2):218235 . 
Van Breda, A. (2001). Resilience Theory: A Literature Review Pretoria, South Africa: South African Military Health Service, Military Psychological Institute, Social Work Research and Development.

Wade, B. and Schenck, C. (2012). "Trauma is the 'Stealing of My Sense of Being Me': A Person-centred Perspective on Trauma" Social Work/Maatskaplike Werk 48(3):340-356.

Walsh, F. (2006). Strengthening Family Resilience New York: The Guilford Press, Second Edition.

Walsh, F. (2007). "Traumatic Loss and Major Disasters: Strengthening Family and Community Resilience" Family Process 46(2):207-227.

Westphal, M. and Bonanno, G. (2007). "Posttraumatic Growth and Resilience to Trauma: Different Sides of the Same Coin or Different Coins?” Applied Psychology 56(3):417-427.

Westphal, M. Seivert, N. and Bonanno, G. (2010). "Expressive Flexibility" Emotion 10(1):92-100.

Wilks, S. and Spivey, C. (2010). "Resilience in Undergraduate Social Work Students: Social Support and Adjustment to Academic Stress" Social Work Education 29(3):276288.

Wortman, C.B. (2004). "Posttraumatic Growth: Progress and Problems" Psychological Inquiry 15(1):81-90.

Zoellner, T. and Maercker, A. (2006). "Posttraumatic Growth in Clinical Psychology: A Critical Review and Introduction of a Two Component Model” Clinical Psychology Review 26(5):626-653. 